\title{
Torsion plastometer trials to investigate the effect of non-proportional loading paths in caliber rolling on damage and performance of metal parts
}

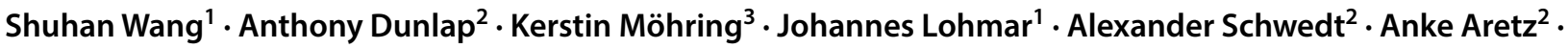 \\ Frank Walther ${ }^{3} \cdot$ Gerhard Hirt $^{1}$
}

Received: 1 August 2019 / Accepted: 19 December 2019 / Published online: 13 January 2020

(c) The Author(s) 2020

\begin{abstract}
The non-proportional loading path describes a strain-dependent development of stress triaxiality and Lode parameter during metal forming processes. Existing studies suggest a strong dependence of damage evolution on the non-proportional loading path. This work focuses on investigating the influence of non-proportional loading paths observed in hot caliber rolling of the case-hardening steel $16 \mathrm{MnCrS5}$ using laboratory scale experiments. The applied torsion plastometer is highly flexible as it can apply combined loading types (tension, compression and torsion) on notched round specimen and enables deformation at elevated temperature. In this study, two characteristic non-proportional loading paths in caliber rolling and the maximal achievable non-proportional loading path variation were recreated in the torsion plastometer based on both FE simulations and experiments. After deformation, the specimen were further analyzed using Scanning Electron Microscopy (SEM) to quantify the damage. The results indicate an influence of the non-proportional loading path on damage evolution. Furthermore, fatigue tests were employed to characterize the fatigue performance of the deformed specimens. In the torsion plastometer trials carried out no clear correlation of performance and damage was observed. This is most likely due to differences in residual dislocation density after static recrystallization and deviations in the microstructure after hot working. Thus, the superposition of microstructure evolution and damage needs to be considered carefully when testing at elevated temperature.
\end{abstract}

Keywords Non-proportional loading path · Triaxiality $\cdot$ Lode Parameter $\cdot$ Caliber rolling $\cdot$ Round to oval $\cdot$ Torsion plastometer trials $\cdot$ Damage characterization $\cdot$ Fatigue tests

\section{Introduction and state of the art}

Caliber rolling is a metal forming process for the production of semi-finished long products that is widely applied in industry. Here the roll sequence round to oval is frequently used for the production of rod-shaped parts due to its favorable temperature distribution and large achievable strain. Due

Shuhan Wang

shuhan.wang@ibf.rwth-aachen.de

1 Institute of Metal Forming (IBF), RWTH Aachen University, Intzestr. 10, 52072 Aachen, Germany

2 Central Facility for Electron Microscopy (GFE), RWTH Aachen University, Ahornstr. 55, 52074 Aachen, Germany

3 Department of Material Test Engineering (WPT), Faculty of Mechanical Engineering, TU Dortmund University, Baroper Str. 303, 44227 Dortmund, Germany to inhomogeneous spreading commonly associated with this roll sequence, the non-proportional loading path, i.e. the stress state evolution during forming, at various locations in the cross section of the work piece can differ greatly. Loading conditions with positive triaxility can induce ductile damage. Thus, a methodology to investigate these characteristic non-proportional loading paths in caliber rolling and their influence on damage evolution independently is sought.

Mechanical tests were adopted in numerous studies to understand the relationship between stress state and damage evolution during plastic deformation. Already in earlier works, mechanical tests were utilized to characterize the effect of triaxility on failure strain. Hancock et al. [1] carried out a series of tensile tests on notched round specimens with various notch geometries and a decreasing ductility with increasing triaxiality was established. In more recent studies, the Lode Parameter was also found to have a strong influence on material fracture, especially at low triaxiality. 
Bao [2] employed a series of tests including upsetting, shear and tensile tests on aluminium alloy and suggested the dominance of shear damage for negative triaxiality. To vary the Lode parameter in material tests Baroum [3] combined tension and torsion to create stress states between shear and tension and identified a change in the rupture mechanism with changing Lode parameter. Bai et al. [4] employed various specimen geometries and load conditions to characterize a 3D fracture locus in dependence of both triaxiality and Lode parameter. To calibrate fracture models, Graham et al. $[5,6]$ presented a modified Lindholm specimen to enable a constant development of triaxiality and Lode parameter with strain. Furthermore, the influence of non-proportional loading paths was investigated in numerous studies. Papasidero et al. [7] made use of a tubular tension-torsion specimen to characterize the onset of ductile fracture in bulk materials at positive stress triaxialities. Wu et al. [8] applied two-step tensile tests and compression tests without lubricant, which promotes non-proportional loading conditions to study this effect on ductile fracture. Non-proportional loading of metal sheets was investigated by Brünig et al. [9] using a specifically designed two-dimensionally loaded $\mathrm{H}$-specimen allowing a wide range of triaxialities and Lode parameters.

All of the above mentioned studies focused mainly on cold forming processes and damage evolution during hot forming has received much less attention. In caliber rolling, damage evolves at elevated temperatures, where the microstructure undergoes constant changes due to recrystallization and recovery during plastic flow, which could influence the damage evolution at microscopic scale. For instance, existing voids can be healed due to recrystallization, as described by Wang et al. [10] and Faini et al. [11]. To study the effect of non-proportional loading path at elevated temperature, the evolution of microstructure needs to be considered and its effect should be ideally separated from that of the loading path. Furthermore, the recreation of characteristic nonproportional loading path extracted from caliber rolling has not been investigated before.

In this work, a torsion plastometer is utilized to recreate characteristic non-proportional loading paths obtained from a round to oval hot caliber rolling sequence. To achieve that both the load conditions and the specimen design have to be adopted based on FE simulations. The specimen are machined, deformed based on the obtained load conditions and afterwards investigated via micrographs and SEM to analyze the microstructure and damage level induced during forming. Finally, fatigue tests are conducted to investigate the performance of the formed parts in dependence of the applied loading paths. The fatigue test is considered as an indirect approach for damage characterization. It is assumed that the voids induced during forming processes are vulnerable points during cyclic loading which contribute to the fracture of the specimen. A decrease of fatigue lifetime due to damage was observed for cold forming in the work of Tekkaya et al. [12], where the test layout ruled out an influence of strain hardening and residual stress.

\section{Materials and methods}

To recreate non-proportional loading paths presented in caliber rolling in the torsion plastometer, a series of experiments were designed based on two different notch geometries that were determined beforehand via FE simulations. Light optical microscopy and SEM analysis were conducted on both the as-received rods as well as the deformed torsion plastometer specimens to investigate the microstructure and the damage levels. Finally the fatigue performance was investigated by means of load increase tests to evaluate the mechanical strength.

The material investigated in this paper is the case-hardening steel $16 \mathrm{MnCrS} 5$. This steel possesses a good machinability and is often used for applications in the automotive industry, such as gear shafts and gear wheels [13]. It was received as a pre-rolled rod with a $60 \mathrm{~mm}$ diameter.

\subsection{Plastic behavior via compression tests}

To characterize the yield behavior, hot compression tests were conducted at different temperatures and strain rates. The specimen were of cylindrical shape with $10 \mathrm{~mm}$ diameter, $15 \mathrm{~mm}$ height and a Rastegaev collar for lubrication. Figure 1 shows the flow curves determined on a servo-hydraulic testing machine using glass powder as lubricant.

\subsubsection{Microstructure characterization via light optical microscopy and electron backscatter diffraction (EBSD)}

To reveal the microstructure of the material, specimens perpendicular to the rolling direction are cut and prepared for further investigation. This preparation includes grinding using $\mathrm{SiC}$ paper with increasing grit size, polishing with a diamond suspension $(6 \mu \mathrm{m}-0.25 \mu \mathrm{m})$ and as final step, a mechanical-chemical polish using a colloidal silica suspension $(0.05 \mu \mathrm{m})$. To identify the microstructural phases, the samples are etched with nital. Micrographs were obtained using the Leica Polyvar Met Light microscope.

Electron Backscatter Diffraction (EBSD) measurements were performed on unetched samples using an EDAX-TSL Hikari camera and OIM Data Collection 7.3 in a field emission gun SEM ("JEOL JSM 7000 F"). An acceleration Voltage of $20 \mathrm{keV}$ was used, mapping a field of $500 \times 500 \mu \mathrm{m}^{2}$ with a step size of $300 \mathrm{~nm}$. The data was analyzed with TSL OIM Analysis 8. 


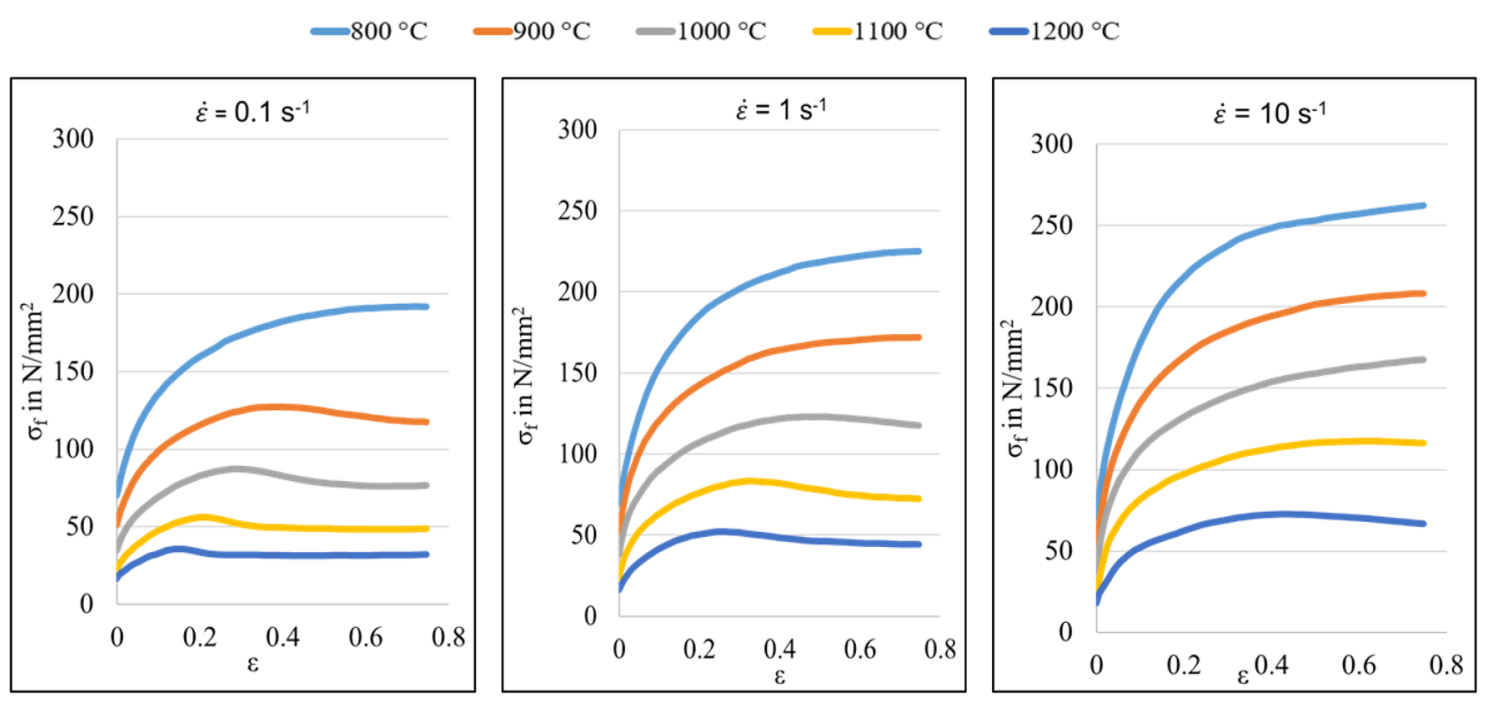

Fig. 1 Flow curves determined in hot compression tests for five temperatures and three strain rates

\subsubsection{Damage characterization via scanning electron method}

Damage quantification tests were performed on the specimen using an automated particle analysis method of the EDAX Genesis (Version 6.53) software in the same SEM. For the SEM investigation polished, non-etched specimen were used. Sample preparation can influence the result of void quantification. Coarse grinding of the sample surface can cause voids being smeared over by the surrounding matrix material, reducing the total void number and area. Subsequent polishing with a mechanical-chemical polish in contrast increases void area by chemically removing material. Inclusions, dropped out during preparation also result in an increase of void area. By keeping the preparation parameters identical for all samples however, these influences can be minimized. The analysis is based on backscatter electron (BSE) images recorded with an acceleration voltage of $15 \mathrm{kV}$ for good elemental contrast. Based on the grayscale contrast in these images, energy dispersive $\mathrm{x}$-ray (EDX) spectroscopy measurements were performed on every detected object in order to identify the object either as inclusion, void or other types of artifacts. The number of voids and the corresponding void area is then analyzed to evaluate damage.

\subsection{The caliber rolling process and its non-proportional loading path distribution}

\subsubsection{Definition of a non-proportional loading path}

The non-proportional loading path refers to the straindependent development of both stress triaxiality and Lode parameter, which together characterize the local stress state in the material during plastic flow under the assumption of isotropy. The stress triaxiality [1], denoted $\eta$, is defined as the ratio of hydrostatic stress and equivalent stress, as shown in Eq. 1. Generally speaking, negative $\eta$ represents compressive stress states while positive $\eta$ represents tensile stress states and $\eta=0$ represents pure shear:

$\eta=\frac{\sigma_{m}}{\bar{\sigma}}$

The Lode parameter can be defined in different ways. Here we adopt the definition given in Eq. 2, that is based on the normalized third deviatoric stress invariant [4] and related to the Lode angle $\theta$ [14] by $\xi=\cos (3 \theta)$. Using this expression, $\xi=1$ is generalized tension, $\xi=-1$ is generalized compression and $\xi=0$ is pure shear.

$\xi=\frac{27}{2} \frac{J_{3}}{\sigma_{e q}^{3}}$

\subsubsection{Process sequence and conditions of caliber rolling}

In this work, the non-proportional loading path developed during hot caliber rolling based on a round to oval sequence is investigated. This sequence is performed at a starting temperature of $1100{ }^{\circ} \mathrm{C}$ and the geometrical conditions are given in Fig. 2, where $d$ represents the diameter of the pre-rolled rod, $w / h$ is the axis ratio of the oval caliber, $\delta$ is the percentage area reduction and $\varepsilon$ is the global true strain. 
Fig. 2 Caliber rolling process with the rolling sequence round to oval
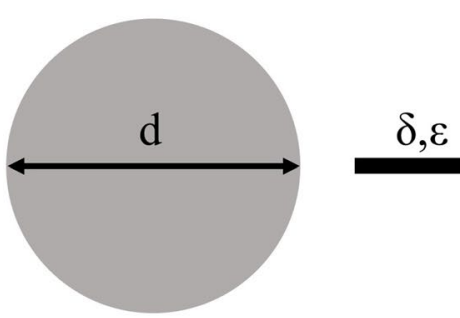

$d=60 \mathrm{~mm}$

$w / h=1.98$

$\delta=0.25$

$\varepsilon=0.29$

\subsubsection{FE simulations to determine the non-proportional loading path in caliber rolling}

In a previous study [15], a FE model in Abaqus Standard was established and the resulting triaxiality and Lode parameter together with several fracture criteria were analyzed using the user subroutine USDFLD. The evolution of triaxiality and Lode parameter for the rolling sequence given in Fig. 2 are presented in Fig. 3. The contours on the left-hand side agree with the expectation of an inhomogeneous non-proportional loading path distribution during plastic deformation. On the right-hand side of Fig. 3, the non-proportional loading paths at three material points marked as P1, P2, P3 are plotted against plastic strain. All points exhibit a varying non-proportional loading path and different magnitudes of strain at the end of plastic deformation.

The material point at the center of the work piece (P2) is subjected only to compression in the deformation zone. At the outer range of the longer axis (P3) the material undergoes a predominantly tensile stress state while at the outer range of the shorter axis ( $\mathrm{P} 1)$, the material point experiences tensile stresses only at the beginning and the end of the deformation.

The Lode parameter is also strongly dependent on peripheral location as shown in Fig. 3. Yet a quite different
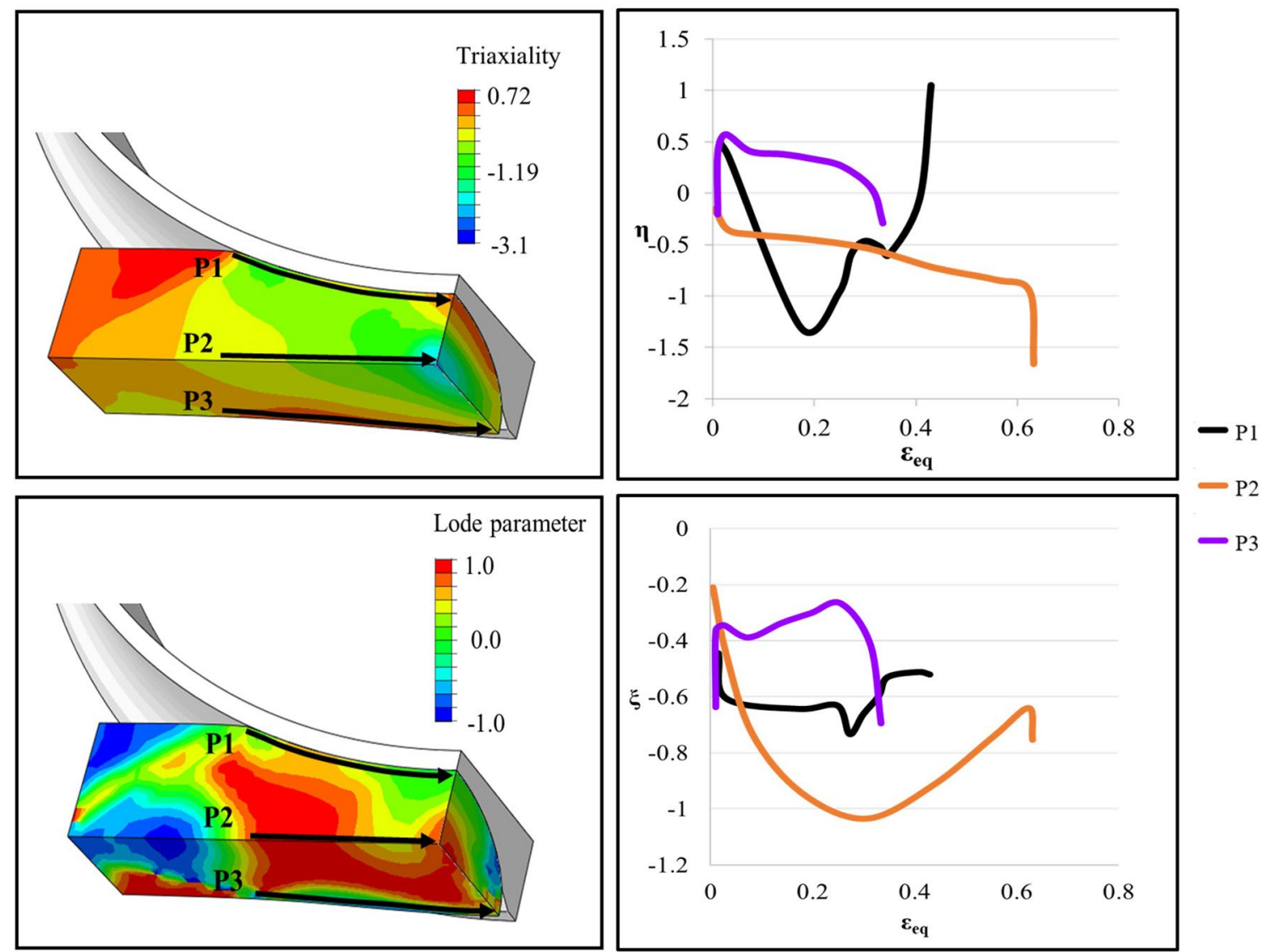

Fig. 3 Development of stress triaxiality and Lode parameter with equivalent plastic strain in three different positions (P1, P2, P3) during caliber rolling 
distribution of the Lode parameter is observed compared to the triaxiality.

\subsection{Recreation of the non-proportional loading path in caliber rolling via a torsion plastometer}

\subsubsection{FE model of the torsion plastometer}

To confirm that the non-proportional loading path of the caliber rolling sequence can be recreated in a torsion plastometer a FE simulation is required. Thus, a thermo-mechanically coupled FE model to capture the effects during hot deformation was implemented using Abaqus Standard. To increase the simulation efficiency, a 2D axisymmetric model was used and the fully integrated 4-node generalized axisymmetric thermally coupled quadrilateral element with twist CGAX4T was adopted for discretization. The element size was chosen to be $0.2 \mathrm{~mm}$ for the notch and $1 \mathrm{~mm}$ for the shaft. The elements in the shaft were deliberately chosen much larger than the elements in the notch since it is assumed that the plastic deformation takes place primarily inside the notch. The initial temperature in the notch was set to be $1100{ }^{\circ} \mathrm{C}$ just like in the caliber rolling process.

In the torsion plastometer experiments, the specimen is heated up using an inductive coil. The modelling of the forming process coupled with magnetic induction would complicate the analysis further and therefore is not considered here. To mimic the skin-effect in induction heating and the heat transfer from the notch center to the gage, an initial temperature field is specified in the model. Furthermore, heat radiation with an emissivity of 0.2 to the surroundings as well as dissipation with an inelastic heat fraction of 0.9 is used. Since the temperature is controlled by the inductive coil through reheating during the experiments, which can be hardly considered in the simulation, the emissivity was deliberately chosen rather low to avoid a large temperature drop. Figure 4 displays the resulting temperature distribution over the cross section after tensile loading for both specimen geometries defined in the following section.

\subsubsection{Specimen geometry design for the torsion plastometer}

The torsion plastometer is designed to enable experiments under various loading types. The aim here is to identify loading types and specimen geometries that recreate the loading paths in caliber rolling. Notched round specimen with two notch geometries are used in the torsion plastometer tests to allow for a variation of triaxiality. The specimen will be afterwards machined into a different geometry for the fatigue tests, aiming to obtain homogenous damage distribution at notch center. According to the work of Bai and Wierzbicki [4], ductility increases with decreasing triaxiality. The

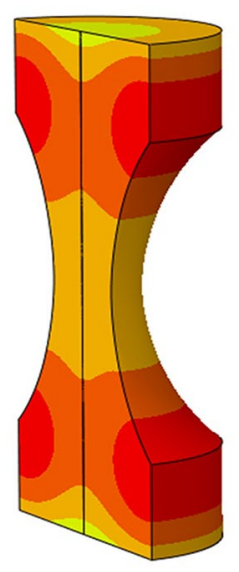

R12

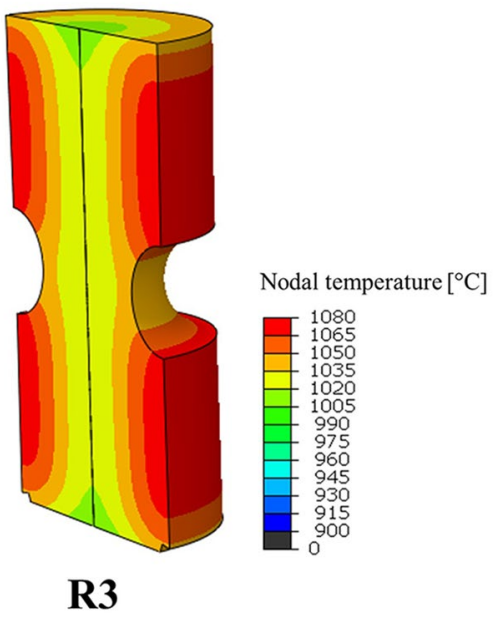

Fig. 4 Temperature distribution in both specimens after tensile loading

influence of Lode parameter increases with decreasing triaxiality and becomes particularly significant in the compressive stress state. With respect to this, for the loading path recreation the triaxiality is considered to be the governing feature on damage in the case of tensile loading (positive triaxiality) and for compressive loading (negative triaxiality) both Lode parameter and triaxiality need to be considered.

For a specimen with a given geometry, the largest possible triaxiality is achieved with pure tension and accordingly the smallest with pure compression. When torsion is imposed, the Lode parameter increases but at the same time the triaxiality decreases according to Eq. 3. In this case, the Lode parameter increases but at the same time the triaxiality gradient shows a sharper drop near the surface so that the mean triaxiality decreases for tensile loading and increases for compressive loading according to the simulation.

Shifting the triaxiality is possible according to [16] by altering the specimen geometry controlled by the term $a / 2 R$ were $a$ is the smallest notch diameter and $R$ is the notch radius. The value of triaxiality at the notch center can be calculated according to Eq. 3 with positive value in the case of tension and negative value in the case of compression [16]:

$\eta= \pm\left(\frac{1}{3}+\sqrt{2} \ln \left(1+\frac{a}{2 R}\right)\right)$

Based on Eq. 3 two specimen geometries were designed with notch radii of $12 \mathrm{~mm}$ (R12) and $3 \mathrm{~mm}$ (R3) respectively, as shown in Fig. 5. The specimen R12 aims to replicate the stress triaxiality evolution present in the caliber rolling process, while $\mathrm{R} 3$ is optimized to recreate the maximal and minimal triaxiality. The triaxiality at the notch center was calculated as \pm 0.74 for geometry R 12 and \pm 1.72 for geometry R3. 
Fig. 5 Specimen with two different notch geometries (R12 and R3) used for torsion plastometer tests
R12

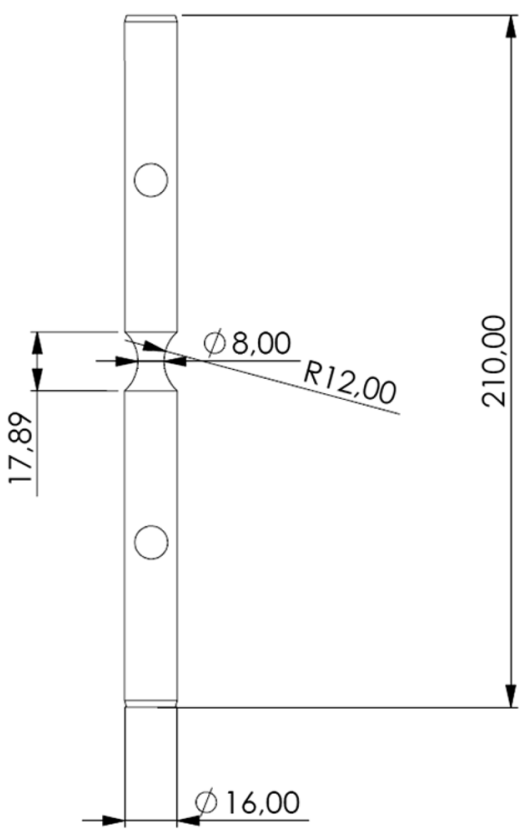

R3

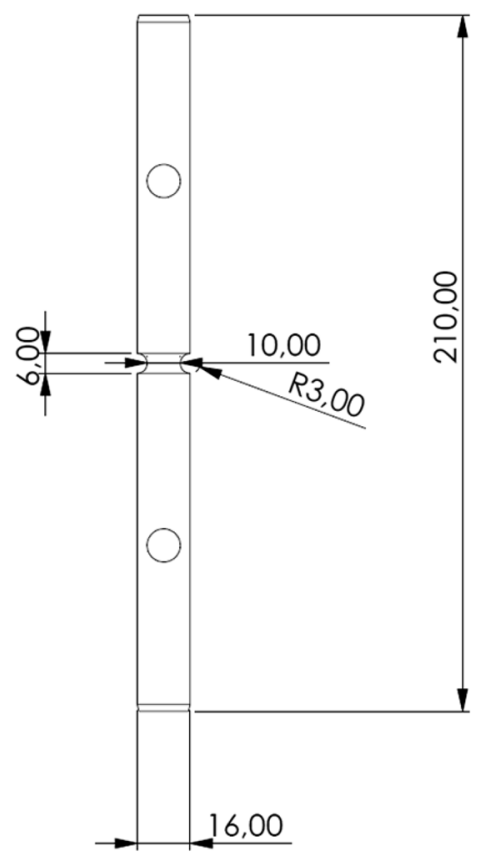

However, the predicted triaxialities and Lode parameters at notch center of R12 and R3 are generally lower than the analytical values and the triaxiality and Lode parameter gradient along the radius is visible in Figs. 6 and 7. The triaxiality of R12 increases from near the surface $(0.4$ at Point C) to the center (0.57 at Point A) after deformation. Similarly, the triaxiality of R3 increases from 0.6 near the surface (Point C) to 0.7 at the center (Point A). As mentioned earlier, the specimens will be further machined into a notch with $5 \mathrm{~mm}$-diameter after forming for the subsequent fatigue tests. This is to ensure a more homogeneous stress state and consequently homogeneous damage distribution at the beginning of the fatigue tests. During the later fatigue tests, where tensile loading is periodically applied, a similar gradient of stress along the radius is expected and consequently crack nucleation should occur in the circular area with higher triaxiality around the symmetry axis (analogous to the area in red color in Fig. 6).

In order to easily compare the predicted triaxiality with the material points from caliber rolling, averaged value of triaxiality and equivalent strain over the cross section area are used for further discussion and also shown in Figs. 6 and 7 using the term "mean value".

\subsubsection{Load conditions for the torsion plastometer}

To recreate an arbitrary non-proportional loading path in the torsion plastometer, tension, compression and torsion can be superimposed. However, pure tension and pure compression are the preferred load conditions for this study as they induce more homogenous conditions in notched specimen with torsion only incorporated to achieve higher strains.

As discussed in Sect. 2.2.3 non-proportional loading paths associated with three material points are considered representative of the investigated caliber rolling process. While material points P2 and P3 show a relatively smooth evolution of the triaxiality with moderate differences between min and max, the evolution of P1 exhibits much higher fluctuations. Thus, only the evolution of material points P2 and P3 will be recreated. For this study, the R12 specimen is adopted and the required amount of equivalent strain is provided by changing the displacement accordingly. It should be mentioned that for one load condition, a small proportion of torsion $\left(27.6^{\circ}\right)$ is superimposed to achieve the strain required for $\mathrm{P} 2$ that lies beyond the maximum possible displacement in compression.

Moreover, to also investigate the extremes in caliber rolling, the maximal (1.0) and minimal (-1.6) triaxiality was approximated using specimen geometry R3. For this study, identical strains in the notch are required to rule out any strain influence on the damage evolution. Due to the temperature gradients in the specimen, discussed earlier, different displacements are required to achieve these comparable strains in the notch.

In Table 1, the four final load conditions determined for the torsion plastometer experiments are given. Load conditions denoted with R12-T and R12-CT are designed for simulating the characteristic triaxiality evolution at P2 and 
Fig. 6 Distribution of triaxiality and Lode parameter in the notch center at the end of deformation for R12-T. Mean values are obtained by averaging the parameters over the $5 \mathrm{~mm}$ radius, into which the specimen will be machined for the fatigue tests

\section{R12 Tension}

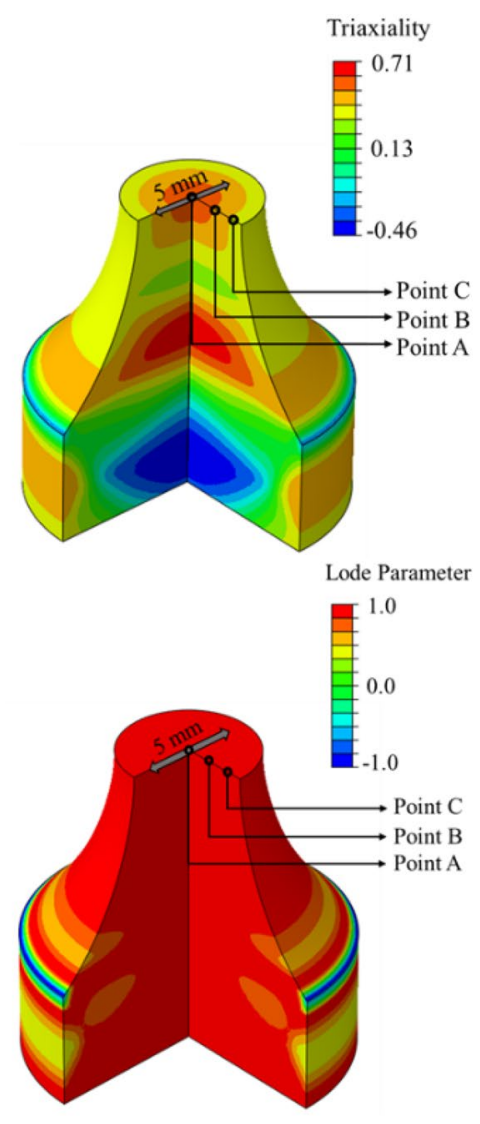

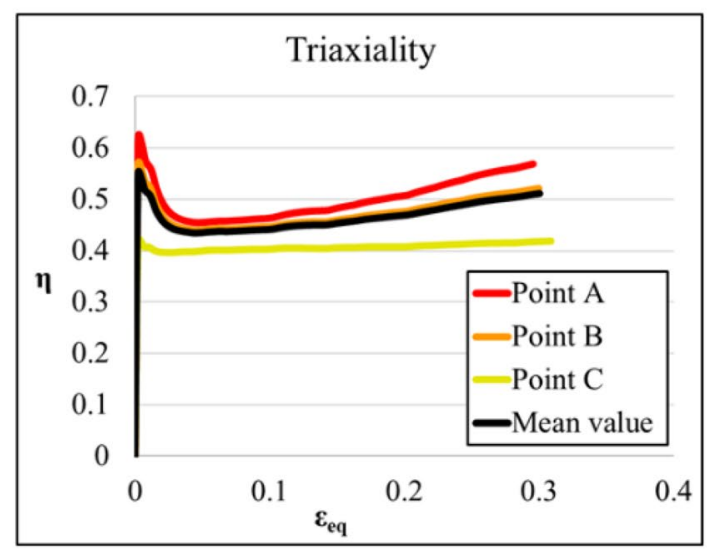

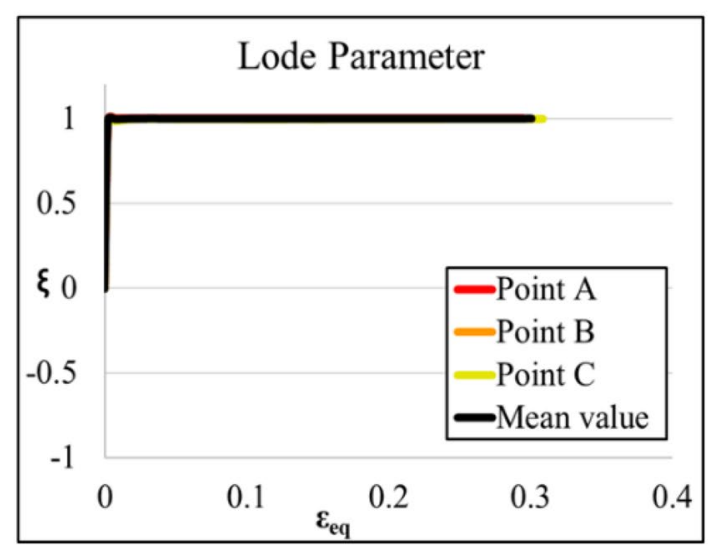

P3 in caliber rolling, respectively. While load condition R3-T and $\mathrm{R} 3-\mathrm{C}$ are designed for recreating the maximal variation in triaxiality.

\subsubsection{Validation of the specimen geometry and load conditions}

A comparison of the non-proportional loading paths developed in caliber rolling and the torsion plastometer is presented in Figs. 8 and 9. On the left side of Fig. 8, the triaxiality of R12-T reaches approximately 0.5 and stays constantly during the whole process. It matches the starting phase of P3 quite well until the triaxiality of P3 starts to drop when the strain reaches 0.14 . It was not possible to recreate this sharp drop in the torsion plastometer. For R12-CT the agreement is good but the high equivalent strains of $\mathrm{P} 2$ are not reached although the compression is superimposed with torsion. The recreation of the Lode parameter is presented on the right side of Fig. 8. For dominant tensile or compressive loading, the Lode parameter is constant around the extreme values ( 1 for tension and -1 for compression). The Lode parameter of $\mathrm{R} 12-\mathrm{CT}$ is roughly in the range of P2. The Lode parameter of P3 is not adequately recreated. Nevertheless, as discussed in Sect. 2.3.1, the exact recreation of the Lode parameter in compression i.e. for $\mathrm{P} 2$ is by far less important than for $\mathrm{P} 3$ where tensile loading prevails.

Figure 9 clearly shows that the analytical value of \pm 1.72 triaxiality calculated from Eq. 3 is not confirmed by the simulation. Instead, the triaxiality achieved by R3-T and $\mathrm{R} 3-\mathrm{C}$ is approximately \pm 0.8 . Hence, the maximal triaxiality variation in caliber rolling could not be entirely reached. A specimen with an even smaller notch radius would be required but would further complicate tensile loading and is very difficult to machine. In summary, the triaxiality values predicted are mostly comparable to those found in caliber rolling and the load conditions should guarantee discernable differences in the results.

Note that in Figs. 8 and 9 the obtained strains in R12-CT and in R3-T are both $25 \%$ higher than that of R12-T and R3-T respectively. Literatures suggest that different level of work hardening is likely to influence the performance in the following load increase fatigue tests. This materialdependent effect is described i.e. in the work of Gupta et al. [17], where an increase of fatigue performance can be observed with strain hardening until a certain level, before the material turns brittle. Here the trials were carried out 
Fig. 7 Distribution of triaxiality and Lode parameter in the notch center at the end of deformation for R3-T

Table 1 Load conditions designed for torsion plastometer tests

\section{R3 Tension}
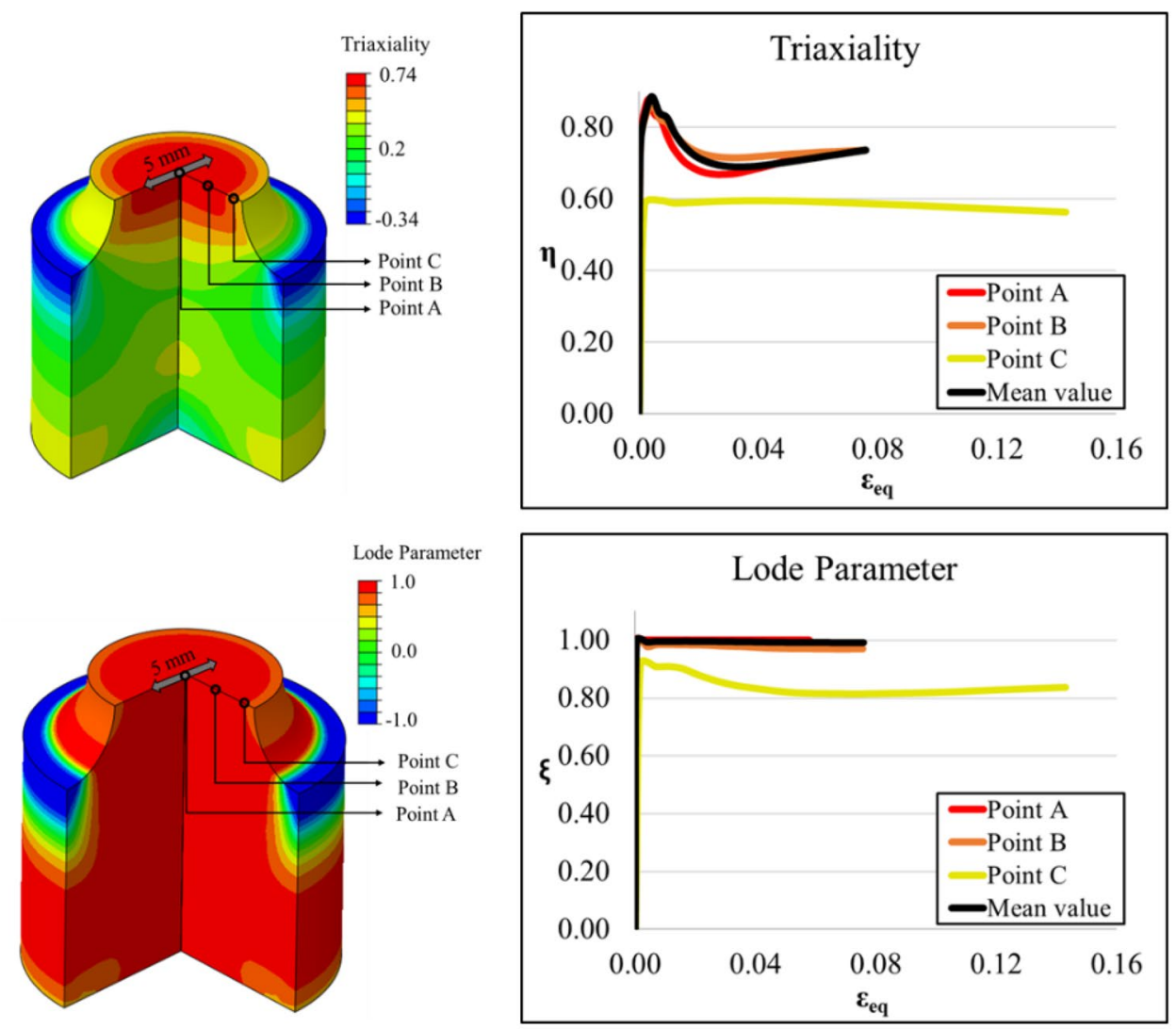

\begin{tabular}{lllll}
\hline & R12-T & R12-CT & R3-T & R3-C \\
\hline Type of specimen & R12 & R12 & R3 & R3 \\
Type of load & Tension & Compression + torsion & Tension & Compression \\
Displacement & $2.3 \mathrm{~mm}$ & $4.42 \mathrm{~mm}+27.6^{\circ}$ & $1.15 \mathrm{~mm}$ & $4.8 \mathrm{~mm}$ \\
Deformation speed & $2.4 \mathrm{~mm} / \mathrm{s}$ & $2.4 \mathrm{~mm} / \mathrm{s}+157 \mathrm{~s}$ & $2.4 \mathrm{~mm} / \mathrm{s}$ & $2.4 \mathrm{~mm} / \mathrm{s}$ \\
Strain at notch center & 0.36 & 0.62 & 0.14 & 0.14 \\
\hline
\end{tabular}
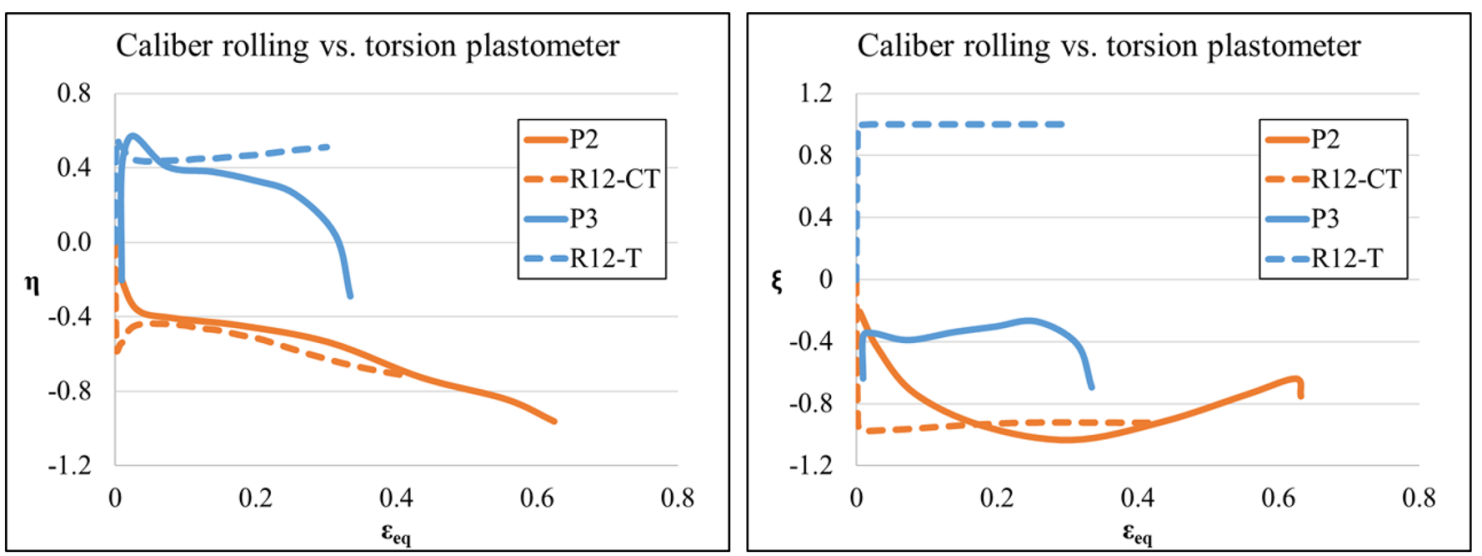

Fig. 8 Recreation of non-proportional loading paths at P2 and P3 in caliber rolling via load conditions R12-T and R12-CT using mean triaxiality and mean Lode parameter over the $5 \mathrm{~mm}$ diameter 


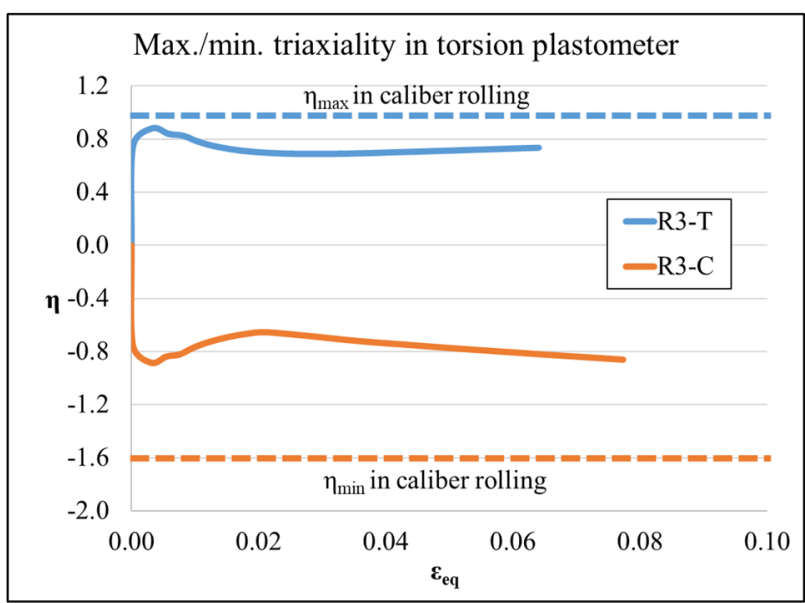

Fig. 9 Comparison of the maximum variation of the mean triaxiality in torsion plastometer with the observed maximum and minimum in caliber rolling

at elevated temperature and the samples were afterwards slowly cooled down. Thus, dislocations developed during plastic strain are assumed to be mostly annihilated during static recrystallization.

\subsection{Experimental torsion plastometer trials}

Twenty-eight experiments were conducted using the torsion plastometer Bähr STD812 shown in Fig. 10 and trials for each of the four load conditions were repeated seven times. The specimen were heated up to precisely $1100{ }^{\circ} \mathrm{C}$ with a heating rate of $6.1{ }^{\circ} \mathrm{C} / \mathrm{s}$ and the temperature was held constant during deformation using an induction coil. An Argon atmosphere was used to avoid any scaling of the specimen. After deformation, controlled cooling with a predefined cooling rate of $0.52 / \mathrm{s}$ was implemented to achieve a ferritic-perlitic microstructure. During deformation, the reaction force and torque was measured using a load cell and the temperature at the center of the notch was measured and controlled using a thermocouple attached to the surface of the specimen.

\subsection{Characterization of the performance via load increase fatigue tests}

For the evaluation of the fatigue performance, the deformed specimen after testing were machined into a geometry shown in Fig. 11. This procedure guarantees that the fatigue results can be compared among each other. Additionally, it reduces the variation in triaxiality. The surface roughness in the notched part of the specimens was manually grinded with emery papers ( 269 up to $5.5 \mu \mathrm{m}$ ) and polished (6.3 up to $1 \mu \mathrm{m}$ ) in order to reduce the influence of the surface condition to the greatest possible extend in accordance with DIN EN ISO 1099:2006.

The fatigue experiments were conducted under standard atmosphere at room temperature. A fully reversed sinusoidal endurance load with the frequency of $1 \mathrm{~Hz}$ and mean stress equal to zero was applied, using the servohydraulic testing machine walter + bai LFV T250 T2500 HH equipped with a $50 \mathrm{kN}$ nominal maximal load cell. For the characterization
Fig. 10 The torsion plastometer Bähr STD812 together with picture and a sketch of a specimen

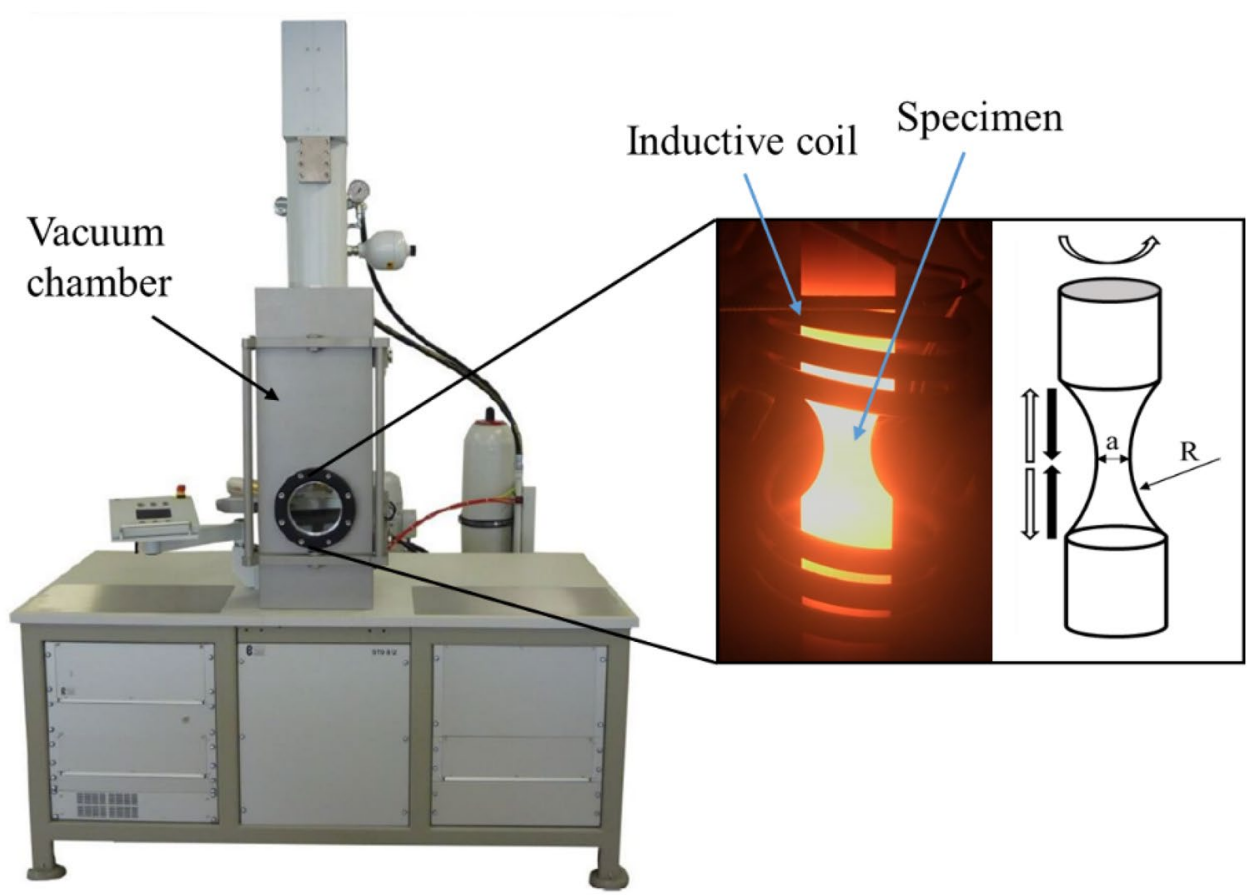


Fig. 11 Specimen used for testing of the fatigue performance
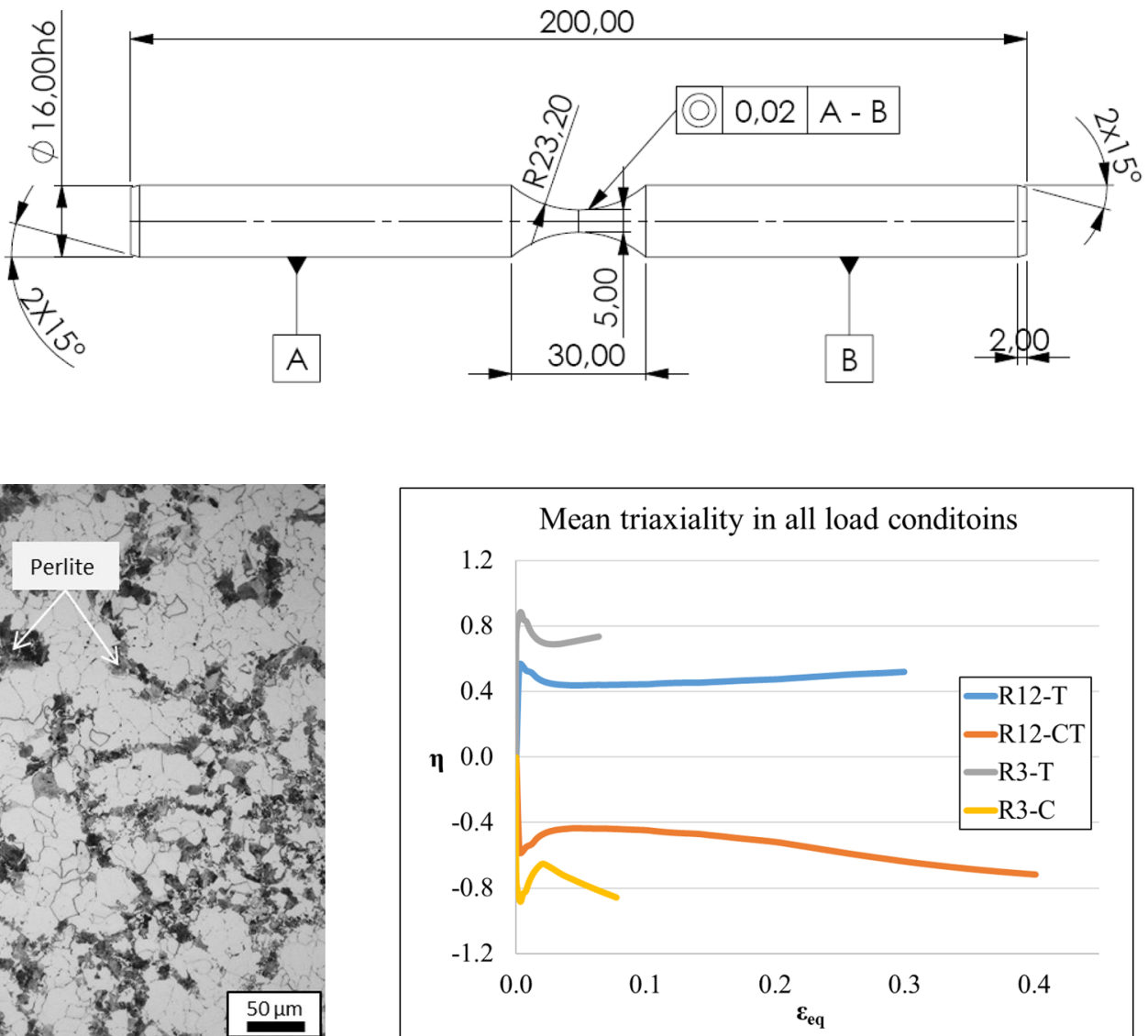

Fig. 13 Mean triaxiality after torsion plastometer tests shown only in a region of $5 \mathrm{~mm}$ diameter around the notch center as only this material is used for subsequent fatigue performance testing. Mean values were acquired in radial direction

microstructure. Pearlite is composed of ferrite and cementite lamella. This microstructure is expected in the low carbon, case hardened steel $16 \mathrm{MnCrS5}$.

\subsubsection{Initial damage}

The damage of the material in its as-received condition was characterized using the method detailed in Sect. 2.1.3. A void area fraction of $1.33 \times 10^{-4}$ with a total void number of 582 voids was detected. Thus, the material already contains some damage owed to the pre-rolling of the as-received rods.

\subsection{FE model validation based on the torsion plastometer trials}

To confirm that the triaxiality evolution predicted for the four load conditions and summarized in Fig. 13 holds, the FE model was validated using the experimental results. The simulated and measured results of the torsion plastometer 
trials listed in Table 1 were compared in terms of material flow and reaction forces.

To validate the material flow, the predicted minimal diameter of the notch (D) and the notch length (L) in the simulations were compared to the experiments. The results and relative deviation are given in Table 2. It can be seen that most of the deviations are lower than $10 \%$. However, D was overestimated for both R12-T and R3-T suggesting less necking in the simulation due to imprecisely predicted temperature fields.

In Fig. 14, the comparisons of the roll force are shown and good agreement between simulation and experiment is
Table 2 Comparison of the geometric features of the specimen between simulations and experiments

\begin{tabular}{|c|c|c|c|c|c|c|}
\hline \multirow[t]{2}{*}{ Load conditions } & \multicolumn{3}{|c|}{$\begin{array}{l}\text { Diameter of the cross section at notch } \\
\text { center }\end{array}$} & \multicolumn{3}{|c|}{ Notch length } \\
\hline & $D_{\text {exp }}(m m)$ & $\mathrm{D}_{\text {sim }}(\mathrm{mm})$ & $\begin{array}{l}\text { Deviation to } \\
\text { experiments (\%) }\end{array}$ & $\mathrm{L}_{\text {exp }}(\mathrm{mm})$ & $\mathrm{L}_{\text {sim }}(\mathrm{mm})$ & $\begin{array}{l}\text { Deviation to } \\
\text { experiments } \\
(\%)\end{array}$ \\
\hline R12-T & 5.95 & 6.86 & +15 & 21.38 & 20.16 & -5.7 \\
\hline R12-CT & 10.53 & 9.7 & -7.9 & 13.81 & 13.95 & +1 \\
\hline R3-T & 8.33 & 9.46 & +13.6 & 6.97 & 6.8 & -2.4 \\
\hline R3-C & 12.10 & 11.48 & -5.1 & 3.62 & 3.57 & -1.4 \\
\hline
\end{tabular}
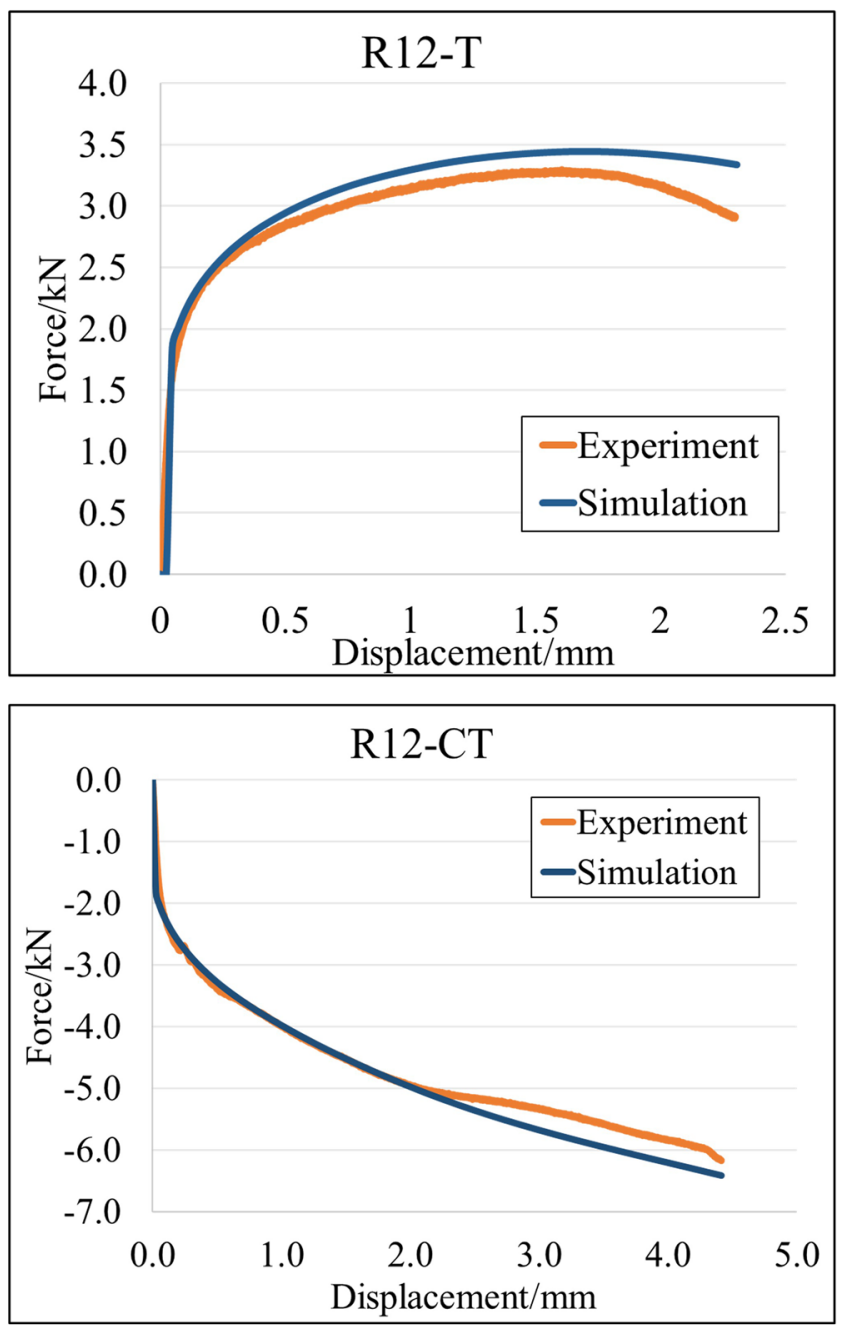
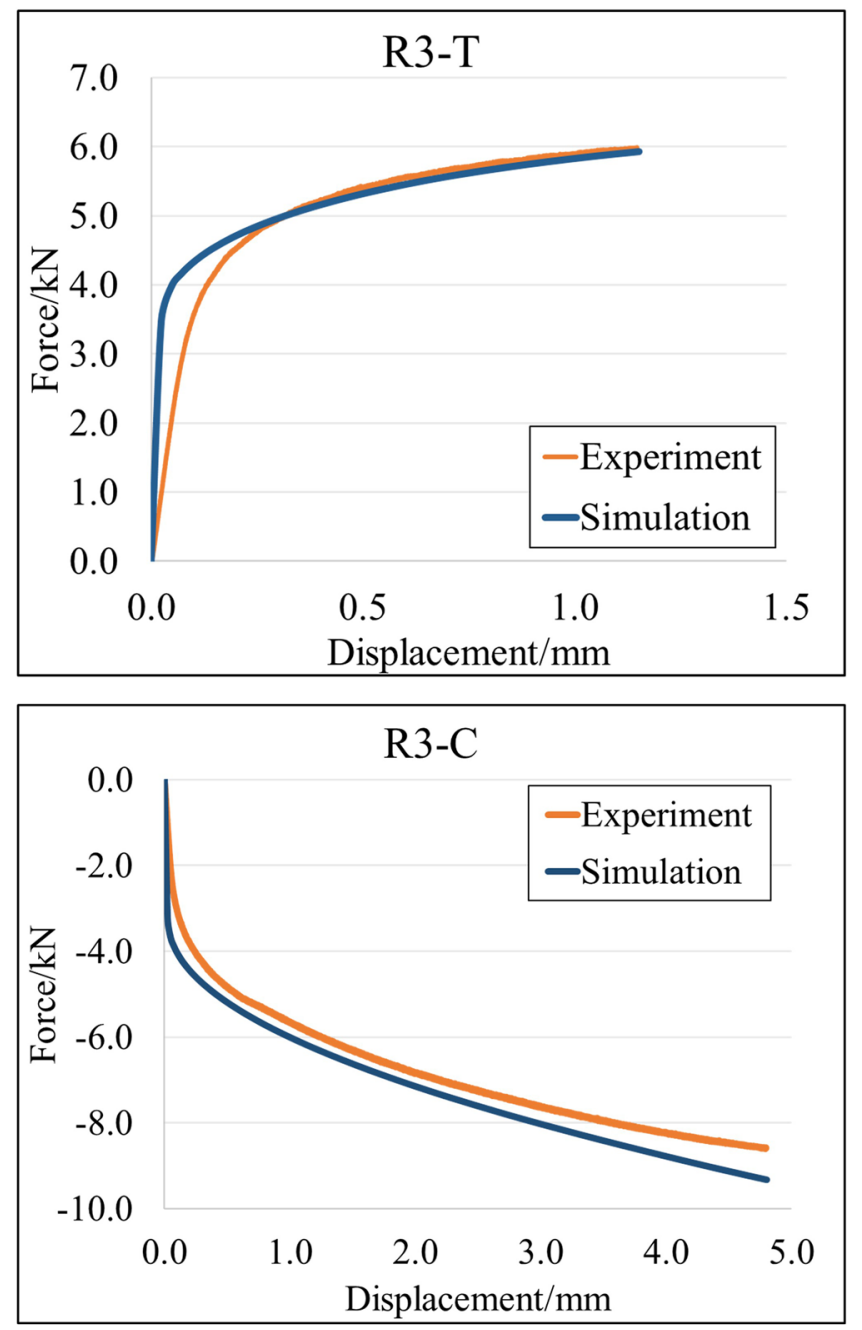

Fig. 14 Validation of FE model based on four load conditions 
found in all cases, although slight differences can still be observed. This is most likely due to the induction heating being only approximated by a reduced emissivity rather than modelled in a fully coupled manner.

\subsection{Final microstructure after the torsion plastometer trials}

Microstructural investigations were performed on the deformed specimens in the center of the notch (Point A in Fig. 6). The procedure to obtain micrographs is detailed in Sect. 2.1.2 and the results are shown in Fig. 15. According to the time-temperature-transformation (TTT) diagram of the $16 \mathrm{MnCrS5}$ case hardening steel, a ferritic-perlitic structure was expected for the used cooling rate of $0.52 / \mathrm{s}$. The images however show a mostly ferritic-bainitic microstructure. All four conditions show the same basic microstructure, with minor differences in phase fraction and grain size among each other.
The samples were further investigated in the same position using EBSD to obtain more information on phase distribution. To distinguish between phases, three indicators are used. Retained austenite is identified by the face centered cubic diffraction patterns. Ferrite, bainite and martensite have similar body centered cubic phases, only differing in carbon content saturation. Martensite is classified based on the Grain Average Image Quality (IQ) described by Ryde and Ramazani et al. [19, 20]. Ferrite and Bainite are distinguished by the Kernel Average Misorientation (KAM) according to Zaefferer et al. [21].

IQ maps and KAM maps are plotted in color scale in Fig. 15. Dark grains in the IQ maps are martensite. The KAM maps show a different bainite fraction for the different geometries (Bainite displayed mostly in green). It is higher in geometry R3 and lower in R12. The results of this classification process are shown in Table 3.

The ferrite in R12-CT is not as clear blue compared with the other conditions. Averaging the misorientation of five ferrite grains showed a near $0^{\circ}$ misorientation for R12-T,
Fig. 15 Grain average Image Quality and Kernel Average Misorientation map for each non-proportional strain path

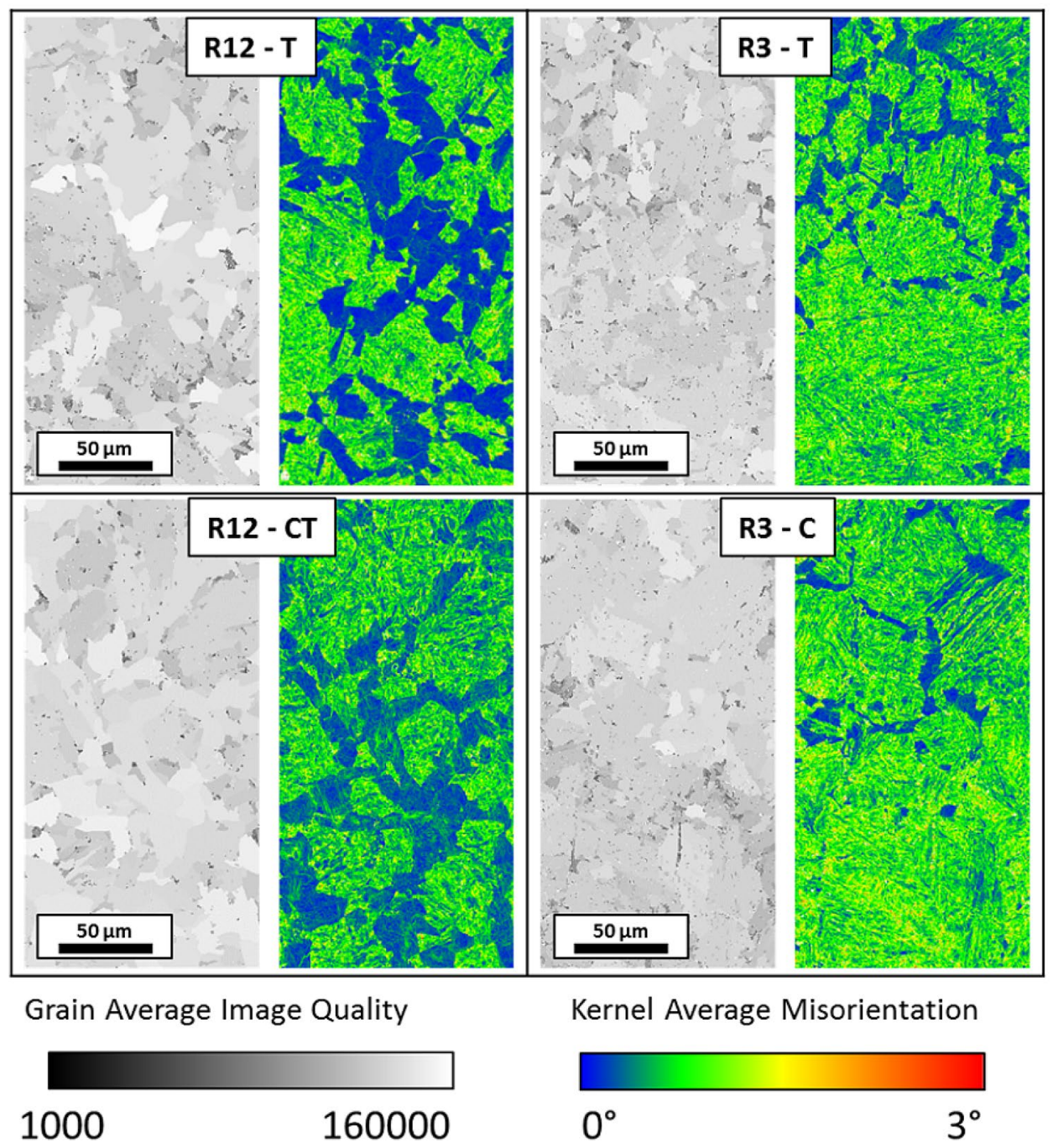


Table 3 Results of the phase analysis of the EBSD data

\begin{tabular}{lllll}
\hline & Ferrite (\%) & Bainite (\%) & $\begin{array}{l}\text { Austenite } \\
(\%)\end{array}$ & $\begin{array}{l}\text { Mar- } \\
\text { tensite } \\
(\%)\end{array}$ \\
\hline R12-T & 61 & 36 & 1 & 2 \\
R12-CT & 61 & 37 & 1 & 1 \\
R3-T & 50 & 46 & 2 & 2 \\
R3-C & 41 & 55 & 2 & 2 \\
\hline
\end{tabular}

R3-T and R3-C, and an average misorientation of $0.3^{\circ}$ for R12-CT. Dislocations due to work hardening can cause this type of misorienation and it indicates that not all dislocations recovered during the cooling process after torsion plastometer trials.

Cooling conditions were identical for each non-proportional strain path, which shows that the phase transformation and the resulting distribution is influenced by load condition and geometry.

\subsection{Damage characterization after the torsion plastometer tests}

To evaluate the damage caused by the different non-proportional loading paths, the void area fraction and void number, obtained using the SEM quantification method, are compared between the load conditions for each specimen geometry in the notch center (Point A in Fig. 6). As homogeneous damage distribution is assumed in the notch after machining the specimen as discussed in Sect. 2.3.2, this position is regarded representative for damage analysis. The results are shown in Fig. 16. The graph in the upper part shows the number of voids in different size ranges, the table below shows the total void area fractions and the total numbers of detected voids.

On the left side of the figure, the measured damage is compared for the specimen $\mathrm{R} 12$, which is designed to recreate the characteristic triaxiality development in caliber rolling. It was noticeable that the damage present in R12-T is much higher than in R12-C. The distribution shows clearly the increase of voids in all sizes after R12-T. Compared with the as-received condition, $\mathrm{R} 12-\mathrm{C}$ shows a reduction of void number and size, most voids larger than $1 \mu \mathrm{m}^{2}$ disappeared. Identical results of the void distribution graph are found when comparing the void area fraction and total void number. This is in accordance with the high triaxiality of R12-T as shown in Fig. 13, since it was found in previous studies that increasing triaxiality in positive region contributes to higher ductile damage. A negative triaxiality on the contrary leads to a reduction of ductile damage by void closure due to negative hydrostatic pressure.

A similar, but not as pronounced effect can also be observed with damages measured for the specimen R3,
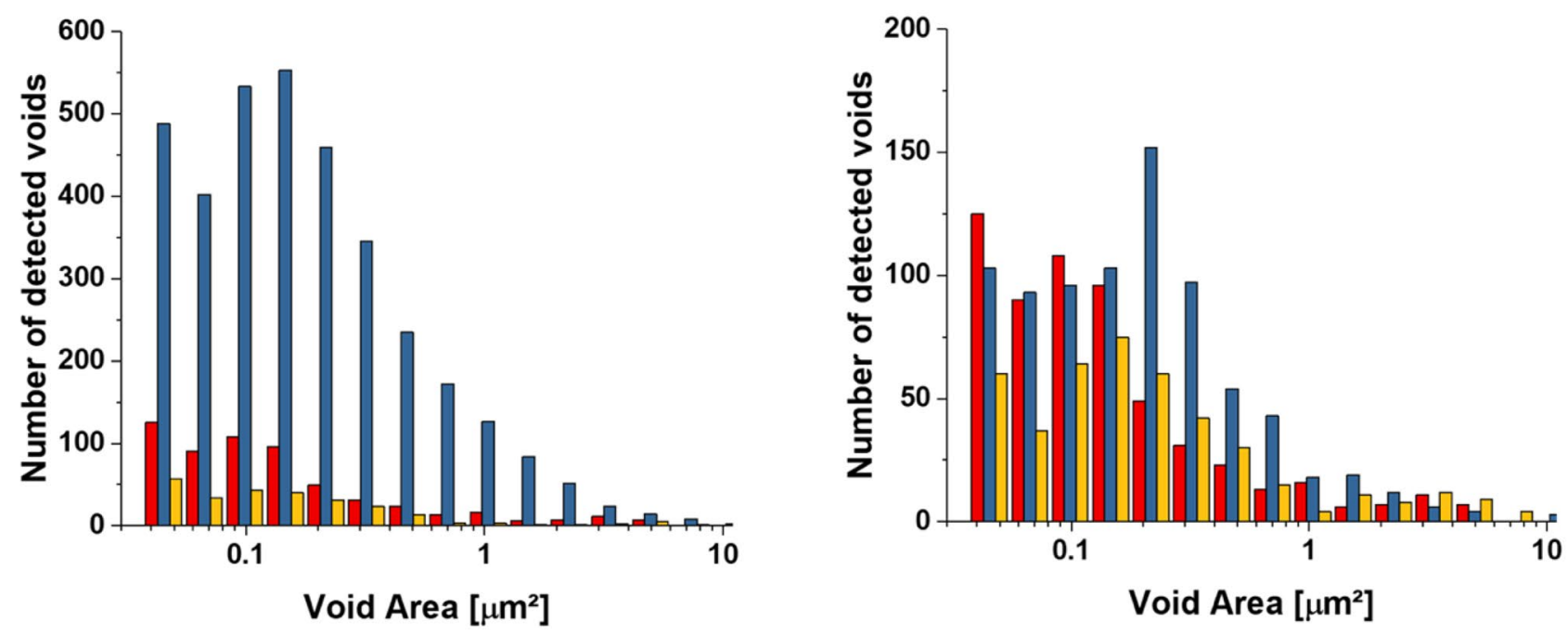

\begin{tabular}{|c|c|c|c|c|}
\hline \multicolumn{2}{|c|}{ R12 } & \multicolumn{2}{|c|}{$\begin{array}{c}\text { Void Area } \\
\text { Fraction }\end{array}$} & $\begin{array}{c}\text { Void } \\
\text { Number }\end{array}$ \\
\hline & As-recieved & $1.33_{\times 10^{-4}}$ & $\pm 0.32_{\times 10^{-4}}$ & 582 \\
\hline R12-T & $8.52_{\times 10^{-4}}$ & $\pm 0.54_{\times 10^{-4}}$ & 3496 \\
\hline R12-CT & $0.70_{\times 10^{-4}}$ & $\pm 0.13_{\times 10^{-4}}$ & 258 \\
\hline
\end{tabular}

\begin{tabular}{|c|c|c|c|c|}
\hline \multicolumn{2}{|c|}{ R3 } & \multicolumn{2}{|c|}{$\begin{array}{c}\text { Void Area } \\
\text { Fraction }\end{array}$} & $\begin{array}{c}\text { Void } \\
\text { Number }\end{array}$ \\
\hline & As-received & $1.33_{\times 10^{-4}}$ & $\pm 0.32_{\times 10^{-4}}$ & 582 \\
\hline R3-T & $2.23_{\times 10^{-4}}$ & $\pm 0.04_{\times 10^{-4}}$ & 804 \\
\hline & R3-C & $1.95_{\times 10^{-4}}$ & $\pm 0.07_{\times 10^{-4}}$ & 433 \\
\hline
\end{tabular}

Fig. 16 Void distribution detected in the varying load conditions, void area fraction and total void number for specimen geometry R12 and R3 
which is designed for maximal variation of triaxiality. The void distribution graph shows a small increase of voids in R3-T and a small decrease in R3-C. This trend is also seen in the total detected void number. The Void area fraction shows a different trend however. Both loading conditions for the R3 specimens have a higher void area fraction compared to the as-received condition. The void distribution shows a higher number of larger voids $\left(>0.2 \mu \mathrm{m}^{2}\right)$, that affect the void area fraction more strongly than the high number of smaller voids in the as-received condition. The smaller difference of damage between R3-T and R3-C can be explained by the relatively smaller strains achieved during torsion plastometer tests.

The measured void area fraction and hence the ductile damage correlates generally with the triaxiality as expected. The individual values measured for each load condition however do not scale precisely with triaxiality as the damage variation between R12-T and the other conditions is higher than expected. The comparably high tensile strain together with the possible dropout of Manganese sulfide inclusions during sample preparation could be an explanation for the greater damage.

\subsection{Fatigue tests to assess the performance of the deformed specimens}

Cyclic experiments were performed to quantify thefatigue performance, and thus obtain an indication for the amount of damage. This is possible, as long as the microstructure of the specimen is sufficiently homogeneous and crack nucleation at the surface can be mostly ruled out.

Three load increase tests per load condition were performed and validated by constant amplitude tests with selected stress amplitudes. The results are shown in Fig. 17 where a decreased number of cycles to failure for the compressive-torsional and the compressive specimen (R12-CT and $\mathrm{R} 3-\mathrm{C}$ ) in comparison to the tensile specimen (R12-T and R3-T) can be seen. This is surprising at first since the negative triaxiality in compression should yield less damage (as found in Fig. 16) and better fatigue performance. The performance of the specimen R12 and R3 is not in agreement with the phase distribution (see Table 3), as the higher bainite content in R3 does not yield more cycles to failure. Moreover, a strengthening effect of bainite induced by smaller average grains cannot be seen.

The reason for the unexpected behavior can most likely be found in the complex and with respect to longitudinal direction inhomogeneous ferritic-bainitic microstructure of the investigated specimen. Generally, the ferrite is the more ductile phase in comparison to bainite and due to this the loci of a significant degree of cyclic deformation in early cycles of the test. However, as Fig. 18 shows, the pre-dominant loci of damage is in the bainitic phase. Due to crack inhabitation (see [22]), a slower crack propagation at voids induced by forming and thus a retarded effect of forming induced damage on the cyclic test can be concluded. Additionally, the extensive crack initiation and micro-crack propagation phase in ferrite takes place only partly supported by the initial damage found.

One further aspect possibly influencing the fatigue performance is the orientation of manganese sulfides with respect to the loading direction in fatigue testing, induced by the strain path of the plastometer trials. As can be seen from Fig. 18 the preferred orientation of the manganese sulfides depends on the load paths used. Due to stress concentration at the interface with the surrounding matrix, these manganese sulfides can be the loci of micro pore nucleation during fatigue. The orientation of these manganese sulfides with regard to the principle strain axis of fatigue testing then influences the local stress state. In turn, the crack propagation and thus the fatigue performance is influenced. This hypothesis can explain the worse fatigue performance of the compressive-torsional (R12-CT) and compressive specimen
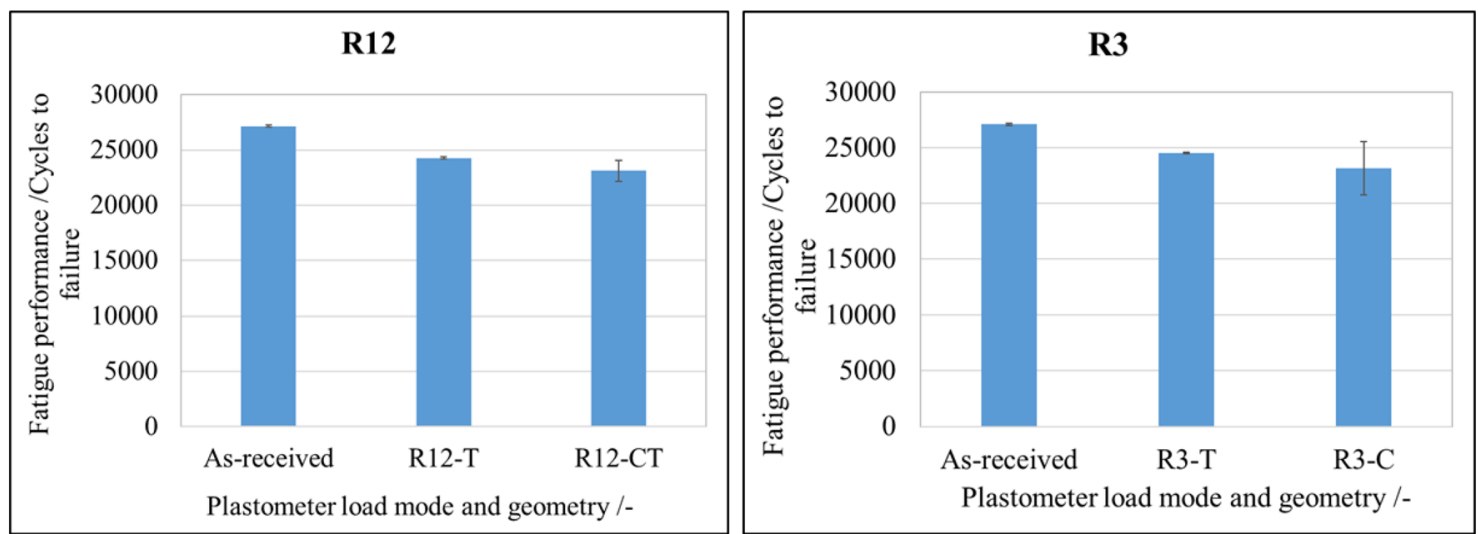

Fig. 17 Fatigue performance after load increase test for specimen geometries R12 and R3 


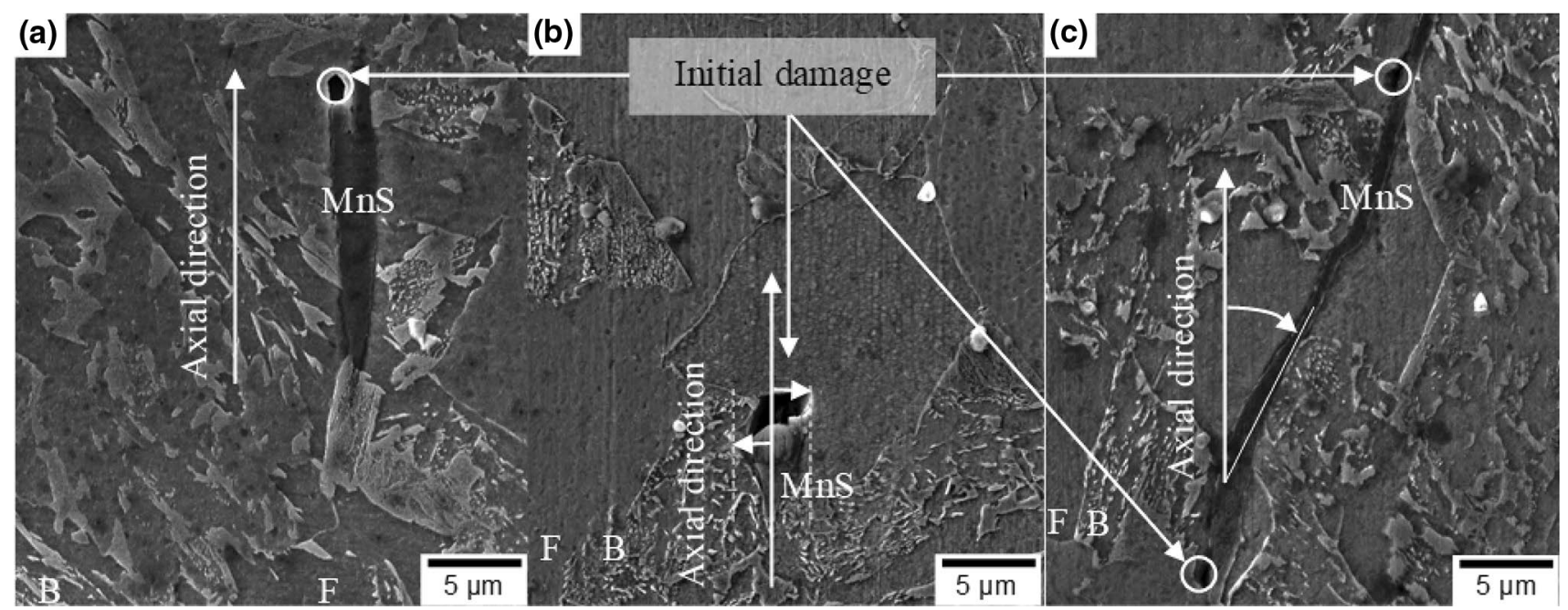

Fig. 18 Example of some positions of $\mathrm{MnS}$ inclusions and initial damage in the ferritic-bainitic ( $\mathrm{F}$ and $\mathrm{B})$ microstructure after $\mathbf{a}$ tensile, $\mathbf{b}$ compressive and compressive-torsional forming

(R3-C) as the orientation of manganese sulfides found in these specimen is inclined.

This argument is supported by results of exemplary performed constant amplitude tests that indicate an even stronger difference between the loading directions for high amplitudes. Here for R12 the difference is 1002 (R12-T) compared to 313 (R12-CT) cycles to failure and for R3 759 (R3-T) compared to 164 (R3-C) cycles to failure, which is equivalent to $70 \%$ difference. Based on these results a strong influence on the crack growth behavior is highly likely.

Finally, fatigue performance can also depend on dislocation density. As presented in Sect. 3.3, full recovery of dislocations was not observed in EBSD for the R12-CT specimen. Nevertheless, the fatigue performance of specimen associated with tensile preloading and especially R12-T is better and thus uncorrelated to the EBSD results. This indicates that residual work hardening due to remaining dislocations is unlikely to be a dominant factor influencing the fatigue tests.

\section{Conclusion and outlook}

In this work, a torsion plastometer is utilized to investigate various non-proportional loading paths occurring during hot caliber rolling as consequence of inhomogeneous spreading and their influence on damage and fatigue performance. Two characteristic non-proportional loading paths from hot caliber rolling were recreated. Furthermore, the maximal possible triaxiality variation was investigated. These investigations required two distinct specimen types with different notch geometries. The non-proportional loading paths realized in the torsion plastometer were in fair agreement with the caliber rolling sequence but the maximal variation of triaxiality in caliber rolling could not be reached as the required notch radius would be impossible to machine.

All tests were conducted at elevated temperature. Recrystallization and recovery as well as subsequent cooling lead to a ferritic-bainitic microstructure that differs from the ferritic-perlitic microstructure of the as-received material. The evolution of microstructure extensively complicates the situation and the separation of its influence from ductile damage mechanisms was not entirely possible in this work even though SEM investigations show a clear influence of the non-proportional loading path on the final damage. Higher damage was found for load conditions where positive triaxiality predominates, while void closure appears during load conditions with negative triaxiality.

The load increase fatigue tests have shown no credible correlation between performance and ductile damage. Although residual work hardening cannot be ruled out completely, it is not considered to be a major influencing factor, since no correlation was found between the fatigue performance and the misorientation due to dislocations measured in EBSD. Rather, microstructure heterogeneity induced in longitudinal direction especially with respect to manganese sulfide orientation during torsional plastometer tests is assumed to influence crack initiation and growth in such a way that the influence of the non-proportional load path is concealed.

In summary, the torsion plastometer can recreate a desired non-proportional loading path at elevated temperature with minor limitations. It allows flexible and fast investigations regarding the influence of non-proportional loading path on final damage and mechanical strength when combined with 
subsequent SEM and fatigue tests. Therefore, flexible laboratory scale experiments should be given more attention in the future for the study of damage-control in metal forming processes.

Acknowledgements Open Access funding provided by Projekt DEAL. The authors gratefully acknowledge the financial support by the Deutsche Forschungsgemeinschaft (DFG, German Research Foundation) for projects A01, B04 and C01 within the TRR188-Project number 278868966 on "Damage Controlled Forming Processes". We also thank the Ministerium für Kultur und Wissenschaft des Landes Nordrhein-Westfalen (MKW NRW, Ministry of Culture and Science of North Rhine-Westphalia) for their financial support within the Major Research Instrumentation Program (servohydraulic tension/torsion testing system, INST 212/378-1 FUGG). The authors wish to thank Xinyang Li from the Institute of Metal Forming for supporting the FE simulations.

Open Access This article is licensed under a Creative Commons Attribution 4.0 International License, which permits use, sharing, adaptation, distribution and reproduction in any medium or format, as long as you give appropriate credit to the original author(s) and the source, provide a link to the Creative Commons licence, and indicate if changes were made. The images or other third party material in this article are included in the article's Creative Commons licence, unless indicated otherwise in a credit line to the material. If material is not included in the article's Creative Commons licence and your intended use is not permitted by statutory regulation or exceeds the permitted use, you will need to obtain permission directly from the copyright holder. To view a copy of this licence, visit http://creativecommons.org/licenses/by/4.0/.

\section{References}

1. Hancock JW, Mackenzie AC (1976) On the mechanisms of ductile failure in high-strength steels subjected to multi-axial stress-states. J Mech Phys Solids 24:147-169

2. Bao Y, Wierzbicki T (2004) On fracture locus in the equivalent strain and stress triaxiality space. Int J Mech Sci 46:81-98

3. Barsoum I, Faleskog J (2007) Ruptuer mechanisms in combined tension and shear-experiments. Int J Solids Struct 44:1768-1786

4. Bai Y, Wierzbiki T (2008) A new model of metal plasticity and fracture with pressure and Lode dependence. Int J Plast 24:1071-1096

5. Graham SM, Zhang T, Gao X, Hayden M (2011) Development of a combined tension-torsion experiment for calibration of ductile fracture models under conditions of low triaxiality. Int J Mech Sci 54:172-181

6. Johnson G, Cook WH (1985) Fracture characteristics of three metals subjected to various strains, strain rates, temperatures and pressures. Eng Fract Mech 21:31-48
7. Papasidero J, Doquet V, Mohr D (2014) Determination of the effect of stress state on the onset of ductile fracture through tension-torsion experiments. Exp Mech 54:137-151

8. Wu B, Li X, Di Y, Brinnel V, Lian J, Münstermann S (2017) Extension of the modified Bai-Wierzbicki model for predicting ductile fracture under complex loading conditions. Fatigue Fract Engng Mater Struct 40:2152-2168

9. Brünig M, Gerke S, Zistl M (2019) Experiments and numerical simulations with the $\mathrm{H}$-specimen on damage and fracture of ductile metals under non-proportional loading paths. Eng Fract Mech 217:106531

10. Wang A, Thomson P, Hodgson P (1996) A study of pore closure and welding in hot rolling process. J Mater Process Technol 60:95-102

11. Faini F, Attanasio A, Ceretti E (2018) Experimental and FE analysis of void closure in hot rolling of stainless steel. J Mater Process Technol 259:235-242

12. Tekkaya AE, Khalifa NB, Hering RMO, Myslicki S, Walther F (2017) Forming-induced damage and its effects on product properties. CIRP Ann Manuf Technol 66:281-284

13. Schmitt M, Schlick G, Seidel C, Reinhart G (2018) Examination of the processability of $16 \mathrm{MnCr} 5$ by means of laser powder bed fusion. In: 10th CIRP conference on photonic technologies, Fürth, Germany

14. Lode W (1926) Versuche ueber den Einfluss der mittleren Hauptspannung auf das Fliessen der Metalle Eisen Kupfer und Nickel. Zeitschrift für Physik 36:913-939

15. Wang S, Pöplau J, Grüber M, Hirt G (2018) Finite element analysis of caliber rolling processes to investigate possibilities to influence the damage evolution, 11th Forming Technology Forum, Zürich, pp 108-112

16. Bridgman PW (1952) Studies in large plastic flow and fracture. MaGrag-Hill, New York

17. Gupta S, Kucharczyk P, Münstermann S, Jayaganthan R (2018) Prestraining induced enhancement in the fatigue limit obtained by load increasing thermal method for metastable austenitic stainless steel. Steel Res Int 89:1700434

18. Dengel D, Harig H (1980) Estimation of the fatigue limit by progressively-increasing load tests. Fatigue Eng Mater 3:113-128

19. Ryde L (2006) Application of EBSD to analysis of microstructures in commercial steels. Mater Sci Technol 22:1297-1306

20. Ramazani A, Pinard P, Richter S, Schwedt UPA (2013) Characterisation of microstructure and modelling of flow behaviour of bainite-aided dual-phase steel. Comput Mater Sci 80:134-141

21. Zaefferer LS, Romano P, Friedel F (2008) EBSD as a tool to identify and quantify bainite and ferrite in low alloyed Al-TRIP steels. J Microsc 230:499-508

22. Guan HYM (2013) Fatigue crack growth behaviors in hot-rolled low carbon steels: a comparison between ferrite-pearlite and ferrite-bainite microstructures. Mater Sci Eng 559:875-881

Publisher's Note Springer Nature remains neutral with regard to jurisdictional claims in published maps and institutional affiliations. 